\title{
Paulo Freire e o pós-colonialismo na educação popular latino-americana ${ }^{1}$
}

\section{Paulo Freire and the postcolonialism in Latin American popular education}

João Colares da Mota Neto

joaocolares@hotmail.com

\section{Resumo}

Este ensaio busca analisar como se apresenta a concepção pós-colonial ao longo das obras pedagógicas de Paulo Freire. $\mathrm{O}$ artigo foi construído com base em pesquisa bibliográfica, que focalizou obras representativas dos diversos momentos da produção intelectual de Paulo Freire, além do estudo de autores representativos da teoria pós-colonial. Conclui-se que a matriz pós-colonial acompanhou as obras de Paulo Freire, desde os seus primeiros trabalhos - em que o colonialismo era visto como um entrave ao desenvolvimento democrático da Nação, passando pelos "escritos africanos" e seu engajamento concreto nas lutas anticoloniais - até os seus últimos trabalhos, em que estava já bastante familiarizado com a crítica epistemológica à modernidade.

Palavras-chave: Paulo Freire, Pós-colonialismo, Educação Popular, América Latina, Autonomia.

\begin{abstract}
This essay intends to analyze how the postcolonial conception is presented along the Paulo Freire's pedagogical works. The article was built based on a literature review, which focused on representative works of the various moments of the Paulo Freire's intellectual production, beyond the study of postcolonial theory representative authors. We conclude that the postcolonial matrix accompanied Paulo Freire throughout his works, since the early ones, in which colonialism was seen as an obstacle to democratic development of the nation, going through the "African writings" and his concrete engagement with anti-colonial struggles, until his last work, which shows his familiarity with the epistemological critique to the modernity.
\end{abstract}

Keywords: Paulo Freire, Postcolonialism, Popular Education, Latin American, Autonomy.

\footnotetext{
${ }^{1}$ Uma primeira versão deste artigo foi originalmente publicada nos anais do I Congreso Internacional de Historia Intelectual de América Latina, evento que aconteceu na cidade de Medellín, na Colômbia, no período de 12 a 14 de setembro de 2012.
}

Revista Educação Online oํ 14, p.25-38, ago./dez. de 2013. 


\section{Introdução}

Neste artigo, ensaiamos a indicação de matrizes pós-coloniais presentes no pensamento do educador brasileiro Paulo Freire (1921-1997), como expressão do seu esforço em reconhecer e lutar contra o legado colonial, presente nas sociedades latino-americanas e, consequentemente, nos modelos pedagógicos que lhes são hegemônicos.

O ensaio é resultante das nossas primeiras aproximações com o tema, que está sendo investigado no contexto de construção da tese Educação popular e decolonialidade na América Latina: um estudo sobre a obra de Paulo Freire e Orlando Fals Borda ${ }^{2}$, vinculada ao Programa de Pós-Graduação em Educação (Doutorado), do Instituto de Ciências da Educação (ICED), da Universidade Federal do Pará (UFPA).

Buscando discutir especificamente a questão "Como se apresenta a concepção pós-colonial na obra de Paulo Freire?", organizamos o artigo em dois tópicos centrais, além dessa introdução e das considerações finais: a) Paulo Freire: um intelectual fronteiriço; b) Paulo Freire e o pós-colonialismo na América Latina.

Nos limites deste artigo, procuramos atentar para o percurso da produção intelectual freireana, desde as suas obras iniciais, com significativa influência de Frantz Fanon e Albert Memmi, considerando, ainda, os seus "escritos africanos" (produto do trabalho de Freire em países africanos em processo de descolonização, na década de 1970), até a última fase de seu pensamento, fortemente influenciado por uma leitura progressista do pós-modernismo.

O referencial teórico deste artigo, além de obras de Paulo Freire, inclui outros autores da educação popular e teóricos pós-coloniais, como Frantz Fanon, Albert Memmi, Stuart Hall, Homi Bhabha e Boaventura de Sousa Santos.

\footnotetext{
${ }^{2}$ O estudo está sendo orientado pela Prof ${ }^{a}$. Dr ${ }^{\text {a }}$. Sônia Maria da Silva Araújo. Como se nota pelo título provisório da tese, optamos por utilizar o conceito de decolonialidade, ao invés do de póscolonialismo para compreender o questionamento à matriz colonial do poder/ser/saber articulado na obra de Paulo Freire e de Orlando Fals Borda. Isso se deve ao fato de darmos primazia, por um conjunto de razões epistemológicas e políticas que aqui não nos é possível aprofundar, ao diálogo com autores latino-americanos vinculados ao "projeto de investigação da modernidade/colonialidade latino-americano", como Enrique Dussel, Walter Mignolo, Aníbal Quijano, entre outros, os quais cunharam o conceito de decolonialidade. Ainda que haja diferenças substanciais entre o decolonial e o pós-colonial, como é esclarecido, por exemplo, por Restrepo e Rojas (2010) muito frequentemente, a decolonialidade tem sido vista como a especificidade do debate latino-americano, no contexto mais geral das teorias pós-coloniais, assim como afirma Santiago Castro-Gómez (2005). Essa é a razão pela qual, neste artigo, ainda estamos trabalhando com o conceito de pós-colonialismo.
}

Revista Educação Online oํ 14, p.25-38, ago./dez. de 2013. 


\section{Paulo Freire: um intelectual fronteiriço}

Paulo Freire é o mais notório educador brasileiro e um dos mais influentes pensadores mundiais da educação do século $\mathrm{XX}$, afirmação que pode ser atestada pelos 41 títulos de doutorado honoris causa recebidos de universidades da Europa, dos Estados Unidos, da América Latina e do Brasil, país em que também foi recentemente considerado Patrono da Educação Brasileira (Lei oㅡ. 12.612/2012).

Não obstante sua notoriedade, concordamos com Henry Giroux (1998), quando afirma que o que tem sido amplamente perdido na apropriação norteamericana e ocidental do trabalho de Freire é a natureza profunda e radical de sua teoria e prática como um discurso anticolonial e pós-colonial. Como forma de apreender essa radicalidade, seguimos Giroux (1998), quando denomina Paulo Freire um intelectual de fronteira.

Como um intelectual de fronteira, Freire quebra o relacionamento entre identidade individual e subjetividade coletiva. Ele faz visível uma política que liga o sofrimento humano a um projeto de esperança, não como um mergulho estático na textualidade sem as lutas humanas, mas como uma política de alfabetização forjada nos deslocamentos políticos e materiais de regimes que exploram, oprimem, excluem, destroem e arruínam a vida humana. (p. 194)

Em nosso entendimento, isso significa captar a complexa movimentação e o incessante trânsito do trabalho de Freire, em torno:

a) das concepções filosóficas que manejou de forma habilidosa, heterodoxa e criativa, cruzando o humanismo cristão, o personalismo, o existencialismo cristão e ateu, a fenomenologia e o marxismo;

b) das apropriações, desconstruções e ressignificações de categorias de pensamento, oriundas tanto da modernidade, quanto do que chamou de pósmodernidade progressista, evitando toda forma de racismo epistemológico;

c) da natureza inextricavelmente política e teórica de sua práxis como professor, intelectual, coordenador de campanhas de alfabetização, secretário de educação, assessor de programas internacionais, colaborador e inspirador de movimentos sociais de resistência;

d) de sua andarilhagem pelo mundo (como gostava de ver sua prática), iniciando no nordeste brasileiro e alçando voos por países diversos da América Latina, pelos Estados Unidos, pela Europa, África, Ásia e Oceania, possibilitando-Ihe 
aprender com o diferente e captar a geopolítica do conhecimento, usando termo de Mignolo (2003).

Não é por outra razão que a leitura de Paulo Freire em todo o mundo tem sido múltipla e, não raro, ambivalente, conforme assinala Rosa María Torres (2007):

A lo largo y ancho del planeta, en los lugares y culturas más diversos, cada quien fue encontrando en Freire esencialmente lo que necesitaba y lo que quería encontrar. $Y$ aquí radica quizás precisamente parte de la explicación acerca de la multiplicidad de lecturas de su obra. Nadie sabrá ponerse de acuerdo sobre qué dijo y qué no dijo. Freire mismo no habría podido asumir - e incluso quién sabe se intuir - la infinitud de Freires a medida que la gente fue inventando por ahí. Desde esta perspectiva, poco importa se unos entendieron mejor a Freire que otros, si hubo quienes comprendieron realmente su pensamiento o no. (p. 27-28)

Nessa perspectiva, o Freire com o qual estabelecemos interlocução neste ensaio é um intelectual que não apenas professou o caráter libertador do diálogo, mas, movendo-se da retórica da ação e dessa àquela, o vivenciou na relação respeitosa com povos, culturas e saberes distintos; um militante que jamais cedeu aos discursos totalitários, deterministas, absolutos, sempre apostando na criação, na história, na utopia, no imponderável; um educador popular disposto a superar fronteiras típicas da modernidade: teoria/prática, ciência/política, indivíduo/sociedade, economia/cultura, professor/aluno, saber científico/saber popular... um intelectual fronteiriço!

Apreender a complexidade do pensamento de Paulo Freire e, nesse contexto, extrair relações possíveis com a problemática pós-colonial, implica em lançarmos um olhar de conjunto e, em movimento, de sua produção intelectual. Aliás, ser fronteiriço, significa também a capacidade de se criticar, superar-se, radicalizar-se, e a obra de Paulo Freire é prenhe de deslocamentos de ênfase, de linguagem, de referencial epistemológico, mantendo, em seu conjunto, o compromisso com uma pedagogia do oprimido, da autonomia, da tolerância, dos sonhos possíveis e da indignação, para se referir a apenas algumas das denominações de suas obras.

É válida, a nosso ver, a proposta de Scocuglia (1999) de identificar um primeiro, segundo e terceiro Paulo Freire, correspondentes, respectivamente, aos escritos realizados entre 1959 e 1970; à sua obra da década de 1970; e aos seus escritos mais recentes nos anos 1980 e 1990. Acrescentaríamos dizendo que o prolongamento do "terceiro Paulo Freire" dá-se com as obras publicadas postumamente, organizadas por Ana Maria Araújo Freire. 
Ao optar por essa leitura cronológica (mas não linear) da obra de Paulo Freire, pretendemos atentar para o transcurso de seu pensamento, no que diz respeito às temáticas pós-coloniais. Estando ciente de que o "pós-colonial" não foi um termo usado no universo de sua obra, apostamos na tese de que a concepção pós-colonial, avant la lettre, sempre esteve lá presente, obviamente com nuanças distintas, em função do contexto histórico plural em que escreveu seus livros (populismo no Brasil; ditadura militar; exílio na América Latina, nos Estados Unidos e na Europa; assessoramento a programas educacionais em países africanos em processo de descolonização; retorno ao Brasil em fase de redemocratização).

No tópico seguinte, buscaremos sugerir algumas relações possíveis entre a obra de Paulo Freire e o pós-colonialismo.

\section{Paulo Freire e o pós-colonialismo na América Latina}

No levantamento bibliográfico realizado para a construção deste artigo, encontramos alguns trabalhos que já indicam relações entre a filosofia do póscolonialismo e a pedagogia freireana, tais como Giroux (1998), Silva (2011), Lima (2011) e Apple (2011).

Em Giroux (1998), para além do que já foi dito anteriormente, encontramos a ideia de que Freire oferece novas possibilidades teóricas para tratar a autoridade e os discursos daquelas práticas casadas com o legado de um colonialismo, "que tanto constroem diretamente ou são envolvidas nas relações sociais, que deixam o privilégio e a opressão vivos como forças ativas constituintes da vida diária dentro dos centros e das margens de poder" (p. 198).

Por sua vez, Silva (2011), ao tratar das teorias pós-críticas do currículo, menciona que a obra inicial de Paulo Freire pode ser considerada como uma espécie de teorização pós-colonial no campo educacional, porque se fundamenta, em parte, nos livros de Frantz Fanon e Albert Memmi. Segundo Silva (2011), o discurso pós-colonial no campo do currículo é "um importante elemento no questionamento e na crítica dos currículos centrados no chamado 'cânon ocidental' das 'grandes' obras literárias e artísticas" (p. 126), reivindicando a inclusão, como fez Freire, das formas culturais que refletem a experiência de grupos cujas identidades são marginalizadas pela identidade europeia dominante. 
Lima (2011), em sua dissertação de mestrado, intitulada Paulo Freire e a pedagogia do oprimido: afinidades pós-coloniais, argumenta que as reflexões presentes na obra em destaque, tal como os estudos pós-coloniais, delineiam uma crítica ao modus operandi do colonialismo, particularmente em sua dimensão cultural e epistêmica, e articulam uma problematização sobre os processos de dominação cognitiva instaurados a partir da colonização europeia no continente latino-americano.

Apple (2011), em artigo no qual analisa o papel do estudioso crítico ativista, tomando como exemplo Paulo Freire, concorda com a possibilidade de "encontros dialógicos", que criam a conexão entre o que chama de imaginação pós-colonial e o trabalho de Freire. Imaginação pós-colonial entendida como subversão das relações de poder ainda existentes, como exame acurado das relações centro/periferia e das questões de autoridade, desestabilizando tradições de identidade herdadas.

Ao mencionar trabalho de Robert Young (2003, apud APPLE, 2011), no qual o pós-colonialismo é concebido como "um nome geral para aqueles conhecimentos insurgentes que vêm do subalterno, do despossuído, e busca mudar os termos sob os quais todos nós vivemos"3 (p. 7), Michael Apple (2011) considera que essa concepção de pós-colonialismo tem claras ressonâncias com os compromissos de Freire, com o que concordamos. No entanto, diz o autor, muito antes da recente disseminação dos estudos pós-coloniais, há uma história secular de luta dos grupos subalternos, que já haviam desenvolvido perspectivas contra-hegemônicas e um extenso número de formas de interromper a dominação colonial na educação. $O$ trabalho de Paulo Freire ganhou notoriedade e ecoou em muitas direções, em grande parte, porque conseguiu conectar-se à memória coletiva dos movimentos sociais de resistência, sugere Apple (2011).

Ao citar apenas esses trabalhos, que articulam a crítica pós-colonial com a obra de Paulo Freire, podemos perceber que o pós-colonialismo não é um termo fácil de ser conceituado. Ora referente a sociedades posteriores à situação colonial, ora às perspectivas epistemológicas que questionam o legado do colonialismo, ora usado no domínio da crítica literária, ora no campo da filosofia e das ciências humanas, o termo carrega ainda a negatividade do prefixo "pós", que define algo

\footnotetext{
${ }^{3}$ Tradução livre do original: "Postcolonialism... is a general name for those insurgent knowledges that come from the subaltern, the dispossessed, and seek to change the terms under which we all live".

Revista Educação Online № 14, p.25-38, ago./dez. de 2013.
} 
pelo que não é, e suas enormes ambivalências, denotando ultrapassagem, contestação, remanescência, entre outros sentidos.

A despeito da diversidade de perspectivas epistemológicas, concordamos com Boaventura de Sousa Santos (2006), quando afirma que elas "têm em comum darem primazia teórica e política às relações desiguais entre o norte e o sul na explicação ou na compreensão do mundo contemporâneo" (p. 28).

Mapeando essa diversidade epistemológica, Silva (2010) afirma que a teoria pós-colonial é constituída por uma matriz de autores assim representados: (1) indianos, africanos e palestinos diasporizados; (2) caribenhos; (3) europeus, especialmente ingleses e portugueses; (4) latino-americanos. Desse conjunto, há, sobretudo, autores que trabalham no âmbito da crítica literária e aqueles que articulam suas ideias no domínio das ciências sociais.

Para além das referências mais recorrentes, nas quais Homi Bhabha, Edward Said e Gayatri Spivak são situados como os founding fathers do pós-colonialismo, há quem reconheça Frantz Fanon, Albert Memmi e Aimé Césaire como os precursores da crítica pós-colonial, pela forte denúncia que empreenderam contra o racismo (tido como um sustentáculo do colonialismo), pelo seu engajamento concreto em movimentos e lutas anticoloniais e pela valorização dos conhecimentos e das experiências de vida dos condenados da terra na estruturação de suas ideias, que devem ser lidas, em nosso entendimento, como uma das mais lúcidas reações contra o colonialismo epistemológico.

Nesse sentido, Albert Memmi (2011[1957]), ao retratar a escola do colonizado, afirma que a memória que é forjada nas salas de aula não é a do próprio povo oprimido, que a história ensinada não é a sua, que os livros lidos lhe falam de um universo que em nada se parece com o seu. Em suas próprias palavras,

Todo parece haber sucedido fuera de su tierra; su país y él mismo están en el aire o solo existen por referencia a los galos, a los francos o al Marne; por referencia al cristianismo, en tanto que él no es cristiano; a Occidente, que se termina delante de sus narices, en una frontera tanto más infranqueable cuanto más imaginaria. (p. 13)

Chama atenção na obra desses autores, especialmente na de Frantz Fanon (2008), não apenas sua contumaz crítica ao colonialismo, como também a presença de uma concepção ética que procura gerar um novo humanismo, sendo esse um forte traço de sua obra pós-colonial e que também está presente na pedagogia 
freireana. "Todas as vezes em que um homem fizer triunfar a dignidade do espírito", diz Fanon (2008, p. 187), "todas as vezes em que um homem disser não a qualquer tentativa de opressão do seu semelhante, sinto-me solidário com seu ato".

Desde a perspectiva de Homi Bhabha (2005), a pós-colonialidade deve ser entendida como um salutar lembrete das relações neocoloniais, ainda vivas no interior da nova ordem mundial e da divisão do trabalho multinacional. Para o crítico literário indiano,

Tal perspectiva permite a autenticação de histórias de exploração e o desenvolvimento de estratégias de resistência. Além disso, no entanto, a crítica póscolonial dá testemunho desses países e comunidades - no norte e no sul, urbanos e rurais - constituídos, se me permitem forjar a expressão, "de outro modo que não a modernidade". (p. 26)

As perspectivas pós-coloniais, ainda segundo Bhabha (2005), emergem "do testemunho colonial dos países do Terceiro Mundo e dos discursos das 'minorias' dentro das divisões geopolíticas de leste e oeste, norte e sul” (p. 239), intervindo nos discursos ideológicos da modernidade "que tentam dar uma 'normalidade' hegemônica ao desenvolvimento irregular e às histórias diferenciadas de nações, raças, comunidades, povos" (p. 239).

De outra forma, o termo se refere "ao processo geral de descolonização que, tal como a própria colonização, marcou com igual intensidade as sociedades colonizadoras e as colonizadas", sendo uma das principais contribuições do termo pós-colonial a capacidade de dirigir atenções "para o fato de que a colonização nunca foi algo externo às sociedades das metrópoles imperiais" (HALL, 2008, p. 101-102).

Considerando esses traços bastante genéricos sobre a concepção póscolonial, mas, a nosso ver, suficientes para os objetivos deste ensaio, é que nos interessa articulá-la com a obra de Paulo Freire, e, neste ínterim, queremos destacar que a matriz pós-colonial presente em sua obra não é uma questão meramente intelectual, uma vez que expressa, sobretudo, o vínculo de Freire com as memórias e os projetos de luta de libertação empreendidos ao longo dos séculos pelos povos latino-americanos. Enrique Dussel (2000) nos ajuda a formular esse argumento:

Freire desenvolve um discurso próprio a partir da realidade das vítimas do nordeste brasileiro e da América Latina, para generalizar sua teoria e prática pedagógica, na África primeiro e, posteriormente, em outros países periféricos, e também centrais. É uma pedagogia planetária que se propõe o surgimento de uma consciência ético- 
crítica. Sua ação educadora tende, então, não só a uma melhoria cognitiva, até das vítimas sociais, ou afetivo-pulsional, mas à produção de uma consciência ético-crítica que se origina nas próprias vítimas, por serem os sujeitos históricos privilegiados de sua própria libertação. $O$ ato pedagógico crítico se exerce no próprio sujeito e na sua práxis de transformação: a libertação assim é o "lugar" e o "propósito" desta pedagogia. (p.443, grifos do autor)

Portanto, uma vez mais, o pós-colonialismo que visualizamos na obra freireana não é um simples exercício de retórica ou uma mera busca de discursos coloniais em suportes textuais pedagógicos. É uma palavra-ação, é denúnciaanúncio, é um processo de luta pela libertação do oprimido, termo genérico, não por falta de clareza de Paulo Freire, mas por compreender os distintos, cruzados e inseparáveis processos de exclusão, não reduzíveis às categorias classe, gênero e etnia, mas as envolvendo seriamente.

Não é à toa que diz Freire (1987) que "não há palavra verdadeira que não seja práxis. Daí, que dizer a palavra verdadeira seja transformar o mundo" (p. 77). Assim, entendemos que sua luta praxiológica contra o colonialismo se apresenta desde as primeiras até as últimas obras, com um vocabulário que vai se modificando ou se ressignificando, embora essa presença nem sempre seja salientada por seus intérpretes.

Em Educação como Prática de Liberdade, por exemplo, escrito em 1965, Freire (1967) inicia o livro falando de sua opção por "uma sociedade que se 'descolonizasse' cada vez mais. Que cada vez mais cortasse as correntes que a faziam e fazem permanecer como objeto de outras, que lhe são sujeitos" (p. 35). É nesse contexto que situa sua proposta emancipadora de educação como um instrumento para a "elevação do pensamento das massas", ou como "politização", citando termo utilizado por Frantz Fanon (2005) em Os condenados da terra. Nesse livro, que sintetiza a primeira fase da produção de Paulo Freire, o colonialismo é visto como uma herança que impedia o desenvolvimento da democracia brasileira. $A$ problemática nacional se apresenta aqui relacionada à educação, que deveria "despertar a consciência do povo" para o enfrentamento de uma sociedade "fechada" e "inexperiente democraticamente", visando a uma sociedade "aberta" e "democrática", livre do jugo colonial.

Trata-se de um anticolonialismo envolvido pela ideologia nacionaldesenvolvimentista da década de 1950, que não preteria a modernidade, antes a 
desejava, vista como superação do estado colonial pela via da democracia. O deslocamento do conceito de "liberdade", forte nessa primeira fase, para o conceito de "libertação", a nosso ver, é ilustrativo da radicalização política de seu pensamento, o que vem a se refletir nas suas posições pós-coloniais. Enquanto liberdade denotada um estado de ser, uma condição ou uma situação, o conceito de libertação enfatiza movimento, processo de luta, emancipação.

Essa passagem reflete tanto a intensificação do engajamento político de Freire, em um contexto de acirramento da ditadura militar que varreu não apenas o Brasil, mas diversos outros países da América Latina e, simultaneamente, o compromisso de Freire com países africanos em processo descolonização, na década de 1970, como também a incorporação, ao nível teórico, do marxismo, representando a importância de conceitos como classe social, trabalho e capital, infra e superestrutura.

A consciência mágica ou ingênua, que Paulo Freire desejava que se elevasse nas obras anteriores, dimensiona-se aqui como "consciência de classe", superadora da "consciência oprimida", "consciência popular" e da "consciência dominada". O livro $A$ ação cultural para a liberdade, que reúne escritos de Freire entre os anos de 1968 e 1974, possui um trecho ilustrativo:

A emersão da consciência popular, mesmo ainda ingenuamente transitiva, provoca o desenvolvimento da consciência das classes dominantes. É que a transitividade ingênua anuncia, nas massas populares emersas, a constituição da consciência da classe dominada, com que se assumem como "classe para si". Desta forma, assim como há um momento de surpresa entre as massas populares quando começam a ver o que antes não viam, há uma correspondente surpresa entre as classes dominantes quando percebem que estão sendo desveladas pelas massas. Esta dupla revelação provoca ansiedades numas e noutras. (FREIRE, 1981, p. 61)

Interessante também notar que, embora Freire trabalhe com termos binários (classes dominantes e dominadas, colonizador e colonizado, opressor e oprimido, consciência crítica e ingênua), a lógica de construção de seu pensamento, como este excerto ilustra, é capaz de captar ambivalências, interseções, cruzamentos, aproximando-o das preocupações mais recentes de teóricos pós-coloniais, como Homi Bhabha (2005) e seus conceitos de entre-lugar e Terceiro Espaço.

Sugerimos que a atenção à ambivalência, em alguma medida, se deve à forte influência de Frantz Fanon em sua obra. Vários dos seus escritos retomam a tese de Os condenados da terra, de que o colonizado é o hospedeiro do colonizador, como 
na Pedagogia do oprimido, representativa do segundo Paulo Freire (1987), quando diz que o conquistador "imprime sua forma ao conquistado que, introjetando-o, se faz um ser ambíguo" (p. 135).

Alguns autores, com efeito, já chamaram atenção para a influência de Fanon na obra de Paulo Freire. E, não apenas isso, destacam a importância estratégica de Freire para a disseminação das ideias de Fanon no Brasil. É o caso de Guimarães (2008), o qual afirma que a Pedagogia do oprimido foi, talvez, a primeira obra na qual um brasileiro incorporou a crítica fanoniana. Lewis Gordon (2008), ao abordar a recepção dos livros de Fanon na América Latina, também destaca a influência de Fanon na obra de Freire. Nos anos 1990, diz ele, "era possível estudar Fanon e Freire em cursos como Teologia Política, Filosofia da Libertação e Pensamento Social Político" (p. 11). Catherine Walsh (2009), em artigo no qual propõe um diálogo entre Freire e Fanon buscando referências para uma pedagogia decolonial na América Latina, destaca as convergências entre seus pensamentos, no que toca às categorias de humanização e libertação e à maneira como articularam as dimensões objetivas e subjetivas da existência em suas análises.

Na década de 1970 e no início dos anos 1980, surgem os "escritos africanos" de Paulo Freire, como denomina Scocuglia (1999), que resultam do seu trabalho na Guiné-Bissau e em outros países africanos que lutavam pela independência da metrópole europeia pela via da construção do socialismo. Conforme esse autor, nessa época, é notória a aproximação teórica de Freire com a obra do marxista italiano Antonio Gramsci e com o pensamento de Amílcar Cabral , líder da luta colonial guineense e do Partido Africano para Independência da Guiné e Cabo Verde (PAIGC).

Amílcar Cabral influenciou enormemente esse momento da produção de Paulo Freire. Cartas à Guiné-Bissau, publicado inicialmente em 1977, é dedicado a esse revolucionário - "A Amílcar Cabral, educador-educando de seu povo" - que ainda aparece citado nessa obra outras 65 vezes. Nesse livro, Paulo Freire reflete sobre sua experiência como assessor internacional na Guiné, colaborando na construção de uma proposta pedagógica capaz de "descolonizar as mentes" ou, nas palavras de Amílcar Cabral, "reafricanizar as mentalidades" (FREIRE, 1978). Denuncia a escola colonial como instituição que reproduz a ideologia colonialista, incutindo nas crianças e nos jovens o estigma de que são "inferiores, incapazes, Revista Educação Online ํo 14, p.25-38, ago./dez. de 2013. 
cuja única salvação estaria em tornar-se 'brancos' ou 'pretos de alma branca'” (p.15) e diz isso, referenciando-se, além de na obra já citada de Fanon, em Albert Memmi (2011 [1957]) de Retrato do Colonizado Precedido pelo Retrato do Colonizador (FREIRE, 1978, p. 15).

Abordando a problemática da "descolonização das mentes" e mostrando que esse tema aparece em Paulo Freire como "conscientização" e em Amílcar Cabral como "africanização dos espíritos", Romão e Gadotti (2012) propõem um interessante diálogo entre as obras desses dois intelectuais/militantes e afirmam que, para ambos, a revolução é permanente, uma vez que a libertação definitiva "não vem com a proclamação da independência política de uma nação, tampouco com sua libertação econômica" (p. 9). A revolução só se afirma "quando o povo dessa nação pós-colonial se liberta das racionalidades que os colonizadores deixaram profundamente enraizadas no solo da consciência dos "ex-colonizados"” (p.9).

Já de volta ao Brasil, após 16 anos de exílio (1964-1979), Freire elaborou trabalhos, muitos dos quais dialogados com outros autores, que continuam evidenciando preocupações pós-coloniais. As suas obras dos anos 1980 e 1990 e as publicações póstumas organizadas por Ana Maria Araújo Freire mantêm o núcleo da fundamentação anterior, que se desdobra em preocupações novas: com escola pública popular, com diferença cultural e a ideia de unidade na diversidade, com o inter/multiculturalismo e a pós-modernidade progressista.

Observamos aqui, um Freire impactado pela crise de paradigmas no campo das ciências e ainda mais convicto da provisoriedade do conhecimento. Aliás, Freire sempre se levantou contra a absolutização do saber e da ignorância, e sua aposta no diálogo (como interação entre sujeitos, conhecimentos e culturas) reflete sua atitude de abertura diante do mundo e da ciência. É assim que vemos que Paulo Freire soube articular noções caras à modernidade (como emancipação, liberdade e democracia) à crítica da própria modernidade, em torno da colonização do conhecimento, expressa em termos de eurocentrismo, determinismo, mecanicismo, temáticas, aliás, bastante evidentes em qualquer crítica pós-colonial contemporânea. Freire passou a identificar suas posições, como querendo enfatizar suas desconfianças com a modernidade, de pós-modernidade progressista. 
O que a pós-modernidade progressista nos coloca é a compreensão realmente dialética da confrontação e dos conflitos e não sua inteligência mecanicista. Digo realmente dialética porque muitas vezes a prática assim chamada é, de fato, puramente mecânica, de uma dialética domesticada. Em lugar da decretação de uma nova História sem classes sociais, sem ideologia, sem luta, sem utopia, sem sonho, o que a cotidianidade mundial nega contundentemente, o que temos a fazer é repor o ser humano que atua, que pensa, que fala, que sonha, que ama, que odeia, que cria e recria, que sabe e ignora, que se afirma e que se nega, que constrói e destrói, que é tanto o que herda quanto o que adquire, no centro de nossas preocupações. (FREIRE, 1993, p. 10, grifos do autor)

Vejamos, então, o quanto o adjetivo progressista, caracterizando 0 substantivo pós-modernidade, nos permite diferenciar as posições de Freire do chamado pós-modernismo lúdico, que, segundo McLaren (1997), que cita como exemplos dessa corrente Lyotard, Derrida e Baudrillard, enfoca "o fabuloso potencial combinatório dos signos na produção de significados e se ocupa com uma realidade que é constituída por uma contínua característica 'brincalhona' do significante e da heterogeneidade de diferenças" (p. 65).

A pós-modernidade progressista de Paulo Freire é o que possibilita ligar a fase mais tardia da sua obra com a crítica epistemológica pós-colonial. Ao recusar o absolutismo da modernidade, mesmo quando ela se proclama dialética, Freire radicaliza sua crítica aos legados do colonialismo e à domesticação que promove das consciências, mesmo das mais revolucionárias.

\section{Considerações Finais}

Neste artigo, procuramos dar visibilidade à matriz pós-colonial que acreditamos estar presente na obra de Paulo Freire. Enfatizar esse aspecto pode contribuir no enfrentamento das versões totalizadoras e eurocêntricas de mundo, marcadamente presentes nas pedagogias que têm orientado os processos educacionais em países colonizados, como os da América Latina.

Paulo Freire nos possibilita pensar uma educação para a autonomia dos povos, a serviço da libertação de homens e mulheres dos domínios do colonialismo, do capitalismo, do patriarcado e do racismo e, por isso, profundamente soberana, democrática e solidária.

Nos limites deste texto, argumentamos que a matriz pós-colonial em Paulo Freire o acompanha ao longo de suas obras, desde os primeiros trabalhos, em que o colonialismo era visto como um entrave ao desenvolvimento democrático da Nação, Revista Educação Online oํ 14, p.25-38, ago./dez. de 2013. 
passando pelos "escritos africanos" e seu engajamento concreto com as lutas anticoloniais, até os seus últimos trabalhos, em que estava já bastante familiarizado com a crítica epistemológica à modernidade.

Apostamos que reler Paulo Freire com a lente do pós-colonialismo nos possibilita, a um só tempo, dar visibilidade a um conjunto de críticas à situação colonial articulado em sua complexa e movediça obra, mas também fazer avançar a teorização mais geral no campo do pós-colonialismo, incorporando as contribuições de Paulo Freire e da pedagogia crítica. Mais do que isso, divulgar um Freire póscolonial nos permite reler sua obra a partir de outros ângulos, atualizá-la; mas, continuando fiel aos seus compromissos, reinventar Freire deve servir para que sua obra continue sendo fonte de inspiração para muitos lutadores e muitas lutadoras pelo mundo afora.

\section{Referências bibliográficas:}

APPLE, Michael W. Paulo Freire, Critical Pedagogy and the tasks of the critical scholar/activist. In. Revista e-curriculum, v. 7, n. 3, p. 1-21, dez. 2011.

ARAÚJO, Sônia Maria da Silva. Educação do campo no Brasil: um discurso para além do pós-colonial? In. Revista Latinoamericana de Ciencias Sociales, Niñez y Juventud, vol. 8, n. 1, enero-junio, p. 221-242, 2010.

BHABHA, Homi. O local da cultura. Belo Horizonte: Editora UFMG, 2005.

CASTRO-GÓMEZ, Santiago. La poscolonialidad explicada a los niños. Popayán: Universidad del Cauca, 2005.

DUSSEL, Enrique. Ética da libertação na idade da globalização e da exclusão. Petrópolis: Vozes, 2000.

FANON, Frantz. Pele negra, máscaras brancas. Salvador: EDUFBA, 2008.

FANON, Frantz. Os condenados da terra. Juiz de Fora: Ed. UFJF, 2005.

FREIRE, Paulo. Educação como prática da liberdade. Rio de Janeiro: Paz e Terra, 1967.

. Cartas à Guiné-Bissau: registros de uma experiência em processo. Rio de Janeiro: Paz e Terra, 1978.

Ação cultural para a liberdade e outros escritos. 5ed. Rio de Janeiro: Paz e Terra, 1981.

. Pedagogia do oprimido. 29ee. Rio de Janeiro: Paz e Terra, 1987. . Política e educação: ensaios. São Paulo: Cortez, 1993. 
GIROUX, Henry. Paulo Freire e a Política de Pós-Colonialismo. In. MCLAREN, Peter; LEONARD, Peter; MOACIR, Gadotti (Orgs.). Paulo Freire: poder, desejo e memórias da libertação. Porto Alegre: ArtMed, 1998. p. 191-202

GORDON, Lewis R. Prefácio. In. FANON, Frantz. Pele negra, máscaras brancas. Salvador: EDUFBA, 2008. p. 11-17

GUIMARÃES, Antônio Sérgio Alfredo. A recepção de Fanon no Brasil e a identidade negra. In. Novos Estudos, n. 81, p. 99-114, julho 2008.

HALL, Stuart. Da diáspora: identidades e mediações culturais. Belo Horizonte: Editora UFMG, 2008.

LIMA, José Gllauco Smith Avelino de. Paulo Freire e a Pedagogia do oprimido: afinidades pós-coloniais. Natal, 2011. Dissertação (Mestrado em Ciências Sociais) Universidade Federal do Rio Grande do Norte, Natal, 2011.

MEMMI, Albert. Retrato del colonizado. Temuko: Wallmapuwen, 2011 [1957].

MCLAREN, Peter. Multiculturalismo crítico. São Paulo: Cortez, 1997.

MIGNOLO, Walter. Historias locales/diseños globales: colonialidad, conocimientos subalternos y pensamiento fronterizo. Madrid: Ediciones Akal, 2003.

RESTREPO, Eduardo; ROJAS, Axel. Inflexión decolonial: fuentes, conceptos y cuestionamientos. Popayán: Universidad del Cauca, 2010.

ROMÃO, José Eustáquio; GADOTTI, Moacir. Paulo Freire e Amílcar Cabral: a descolonização das mentes. São Paulo: Editora e Livraria Instituto Paulo Freire, 2012.

SANTOS, Boaventura de Sousa. A gramática do tempo: para uma nova cultura política. São Paulo: Cortez, 2006.

SCOCUGLIA, Afonso Celso. A história das ideias de Paulo Freire e a atual crise de paradigmas. João Pessoa: Editora Universitária, 1999.

SILVA, Tomaz Tadeu da. Documentos de identidade: uma introdução às teorias do currículo. 3ed. Belo Horizonte: Autêntica, 2011.

TORRES, Rosa María. Los múltiples Paulo Freires. In. Educación de Adultos y Desarrollo - dvv international, n. 69, p. 15-29, 2007.

WALSH, Catherine. Interculturalidade, crítica e pedagogia decolonial: in-surgir, reexistir e re-viver. In. CANDAU, Vera Maria (Org.). Educação intercultural na América Latina: entre concepções, tensões e propostas. Rio de Janeiro: 7 Letras, 2009. p. 1242.

Revista Educação Online ํo 14, p.25-38, ago./dez. de 2013. 